\title{
Embedded together: The life and death consequences of interaction of the Bcl-2 family with membranes
}

\author{
Brian Leber • Jialing Lin • David W. Andrews
}

Published online: 15 February 2007

(C) Springer Science + Business Media, LLC 2007

\begin{abstract}
Permeabilization of the outer mitochondrial membrane is the point of no return in most programmed cell deaths. This critical step is mainly regulated by the various protein-protein and protein-membrane interactions of the Bcl-2 family proteins. The two main models for regulation of mitochondrial outer membrane permeabilization, direct activation and displacement do not account for all of the experimental data and both largely neglect the importance of the membrane. We propose the embedding together model to emphasize the critical importance of $\mathrm{Bcl}-2$ family protein interactions with and within membranes. The embedding together model proposes that both pro- and anti-apoptotic Bcl-2 family proteins engage in similar dynamic interactions that are governed by membrane dependent conformational changes and culminate in either aborted or productive membrane permeabilization depending on the final oligomeric state of pro-apoptotic Bax and/or Bak.
\end{abstract}

Keywords $\mathrm{Bcl}-2 \cdot \mathrm{Bax} \cdot \mathrm{MOMP} \cdot$ Mitochondrial permeabilization $\cdot$ Membrane proteins

\section{B. Leber}

Departments of Biochemistry and Biomedical Sciences and

Medicine, McMaster University,

Hamilton, Ontario L8N 3Z5, Canada

\section{J. Lin}

Department of Biochemistry and Molecular Biology,

University of Oklahoma Health Sciences Center,

Oklahoma City, Oklahoma 73190, USA

D. W. Andrews $(\triangle)$

Departments of Biochemistry and Biomedical Sciences,

McMaster University,

Hamilton, Ontario L8N 3Z5, Canada

e-mail: andrewsd@mcmaster.ca

\section{Introduction}

There is a growing consensus that most programmed cell deaths (including apoptosis) are composed two distinct phases, initiation and execution. Bcl-2 family proteins function primarily during the initiation of apoptosis. These proteins carry the moniker of $\mathrm{Bcl}-2$ family proteins to indicate that they share sequence similarity with $\mathrm{Bcl}-2$, the prototype of the family. Bcl-2 and its closest relatives, Bcl-XL, Mcl-1, Bcl-w and A1 share 4 regions of similarity denoted $\mathrm{BH}$ (Bcl-2 homology) regions. For most cells the commitment step that separates initiation from execution appears to be permeabilization of the outer mitochondrial membrane. It is at the commitment step that many intracellular signals must be integrated to determine the fate of the cell. Therefore, it is not surprising that mitochondrial outer membrane permeabilization (MOMP) is a point of convergence for a large variety of signaling pathways. Many of these signals are mediated by proteins of the Bcl-2 family called BH3only proteins because the only sequence similarity is a $\mathrm{BH} 3$ sequence. It is likely that the rest of the protein sequence of $\mathrm{BH} 3$-only proteins is divergent because these proteins have other functions in healthy cells. Unlike BH3-proteins, the major apoptosis function of multi-BH region $\mathrm{Bcl}-2$ family proteins is directly regulating the commitment step. In part convergence is driven by the fact that permeabilization is mediated by a small number of largely functionally redundant proteins, typically just Bax and Bak (and in some cells perhaps Bok). These pro-apoptotic proteins that contain $\mathrm{BH}$ regions 1-3 integrate signals from the $\mathrm{BH} 3$-only and other proteins generally via direct binding interactions.

MOMP, by releasing a number of proteins from the mitochondrial intermembrane space that participate in cellular execution, drives divergence of the process. Execution spreads throughout the cell when the proteins released from 


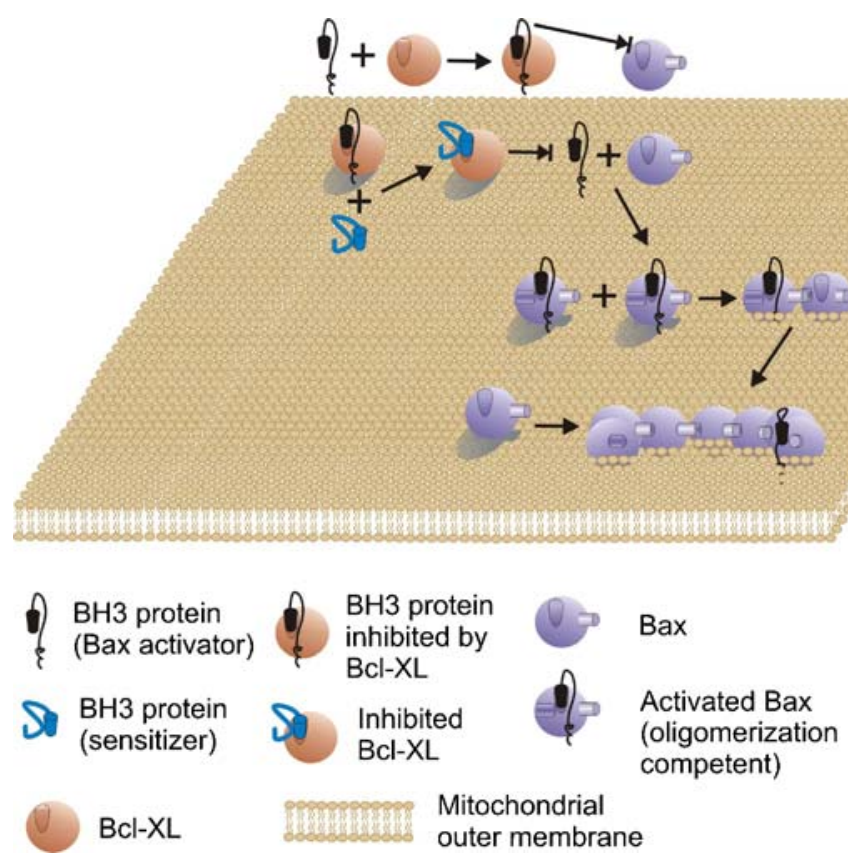

Fig. 1 The direct activation model. An activator protein (black) such as tBid that contains a $\mathrm{BH} 3$ motif can bind to and activate Bax (powder blue). Activation of Bax leads to integration in the MOM and oligomerization. Oligomerization of Bax may displace the activator. Alternatively, one activated Bax may recruit additional Bax and therefore, there need be only one activator for each oligomer. Bak is predicted to function similarly but begins bound to the surface of MOM. Mem-

the intermembrane space each interact with a variety of other proteins that carry out cellular execution. These interactions activate both the proteases, including the caspases, as well as the nucleases that physically demolish the cell.

Cell free models using purified proteins have demonstrated unequivocally that once activated, either Bax or Bak is sufficient to permeabilize a variety of membranes including liposomes. Nevertheless, it is likely that in cells these proteins rarely if ever act alone. Instead they not only integrate cellular signals via direct binding interactions but also probably interact with other mitochondrial outer membrane (MOM) constituents (proteins and lipids) to carry out MOMP. In this review we will examine what is known about the molecular mechanism(s) by which Bax and Bak permeabilize MOM. We describe and critique two of the current models for the process (Direct Activation and Displacement) and use this information as well as other data to synthesize a new model (Embedding Together) to explain different aspects of the molecular mechanism. We describe some of the shortcomings of each of these models as well as prescribe experimental approaches for testing the salient features of each.

\section{Direct activation model}

In the current formulation [1-3] the main features of the direct activation model (Fig. 1) are as follows: BH3-only brane permeabilization is inhibited by anti-apoptosis proteins (such as $\mathrm{Bcl}-\mathrm{XL}$, brown) binding to the activator protein. Once bound to Bcl-XL the activator protein can no longer bind to or activate Bax. Sensitizer proteins (cyan) compete with activator proteins for binding to Bcl-XL. Therefore, if the affinity for Bcl-XL or abundance of the sensitizer is greater than the activator the sensitizer will displace the activator from $\mathrm{Bcl}-\mathrm{XL}$ whereupon the activator can again bind to Bax

proteins are classified as activator or sensitizer (derepressor) proteins based on their multi-BH motif containing binding partners. Activators (Fig. 1, Black) are the BH3-only proteins that bind both pro- and anti-apoptotic proteins such as Bax and Bcl-XL, respectively. In the direct activation model, Bax activation requires direct interaction with at least one of the BH3-only activators. Bcl-XL sequesters the BH3-only activators, and thereby prevents the activation of Bax. In contrast, sensitizer BH3-only proteins (Fig. 1, Cyan) bind antiapoptotic proteins releasing the activator $\mathrm{BH} 3$-only proteins from Bcl-XL. In the original version of the direct activation model $\mathrm{Bcl}-\mathrm{XL}$ was also proposed to sequester activated Bax or Bak however, this activity is now usually excluded and often relegated to the status of a detergent induced artifact. At the very least it is secondary to the sequestration of BH3-only activators in the current version. Indeed, this has become a distinguishing feature of current direct activation models.

The direct activation models do not explicitly distinguish between which multi-BH domain pro-apoptotic proteins are being activated, either Bax or Bak. In most, but not all, model systems Bax and Bak function in a redundant, parallel fashion [4]. However, elucidating the molecular mechanisms entailed by a direct activation model will require separate investigations of both proteins, as activating Bax requires membrane localization and possibly integration into the MOM before oligomerization, whereas activating Bak requires only 
the last step. Thus, unless the migration to membranes, integration and oligomerization of Bax occur in one concerted step resulting from a single conformational change (and there is evidence from both endogenous and viral regulators of $\mathrm{Bax}$ activation that these are separate steps-see Section 4.1), Bax and Bak activation require different mechanisms.

BH3-only proteins Bid and Bim are the primary activators proposed in the direct activation model, although PUMA is sometimes considered an activator [5]. Consistent with this view, a peptide corresponding to the $\mathrm{BH} 3$ motif of either $\mathrm{Bid}$ or Bim induced soluble monomeric Bax protein to insert into liposomal membranes with a composition of lipids often used as a mimic of mitochondrial outer membranes (MOM-like liposomes). Once activated, Bax forms oligomers in these MOM-like liposomes and causes membrane permeabilization [2]. Bid and Bim peptides also induced Bax insertion into the MOM, Bax and Bak oligomerization as well as cytochrome $c$ release from mitochondria isolated from various tissues or cell lines $[1-3,5,6]$. Bax or Bak was required for either of these peptides to release cytochrome $c$ from mitochondria [1,6]. Moreover, when loaded into various cells, each peptide was sufficient to trigger cytochrome $c$ release and apoptosis $[1,2,6]$.

Consistent with these data, recombinant tBid protein activated full length, recombinant Bax to permeabilize MOM liposomes and isolated mitochondria [7-11]. As part of this process, $\mathrm{tBid}$ causes Bax to insert into membranes and form large molecular weight oligomers [2, 5, 7, 10-12]. Full length, uncleaved Bid activates endogenous Bax in isolated mitochondria, but is less potent compared to tBid [13, 14]. Bid and tBid also induce cytochrome $c$ release from mitochondria by activating and oligomerizing endogenous Bak $[13,15,16]$.

The role of Bim as a $\mathrm{BH} 3$-only activator has not been studied as extensively as $\mathrm{tBid} / \mathrm{Bid}$, and the results are complicated by the existence of multiple splice isoforms and post-translational modifications of Bim. Nevertheless, studies done to date do point to significant differences between Bid and Bim. Recombinant Bax can be activated by purified BimEL protein (but not BimL) to release cytochrome $c$ from mitochondria [17]. However, compared to tBid, BimEL was less effective at releasing cytochrome $c$ from mitochondria. Furthermore, while tBid releases $10-\mathrm{kDa}$ molecules from liposomes when combined with Bax protein, BimEL with Bax generated smaller pores that released only 0.4$\mathrm{kDa}$ molecules [9]. Thus in cell free systems, BimEL may be an incomplete activator of Bax. Consistent with incomplete activation, in cells transfected with BimS and BimAD, Bax changes conformation and induces apoptosis, but Bim $\mathrm{S} / \mathrm{AD}$ does not bind to inactive Bax in cells solubilized with CHAPS, indicating that another activation step for Bax is required before it interacts with Bim [18]. Similarly, BimEL was co-precipitated with Bax in mitochondria from hematopoeitic cells only after apoptosis induction by IL-3 withdrawal; phosphorylation of BimEL inhibited the interaction [19]. Whether any Bim isoforms can activate Bak directly remain to be determined by reconstitution experiments similar to those performed for tBid.

The status of PUMA as a Bid-like activator of Bax is even more controversial, as a PUMA BH3 peptide and purified PUMA protein acted like an activator in one study [5] but like a sensitizer in two other studies [2, 3].

How Bax and Bak are activated by BH3-only activators is unclear. The NMR structure of soluble monomeric Bax indicates that the C-terminal hydrophobic helix (helix 9) is buried in the hydrophobic groove that corresponds to the hydrophobic groove of Bcl-XL demonstrated by crystallography to be a $\mathrm{BH} 3$ binding pocket $[20,21]$. Therefore, by analogy, the BH3 motif of tBid or Bim may bind to the similar hydrophobic groove in Bax displacing helix 9, which then inserts into the mitochondrial membrane. If this is true, Bak must be activated by a different mechanism since the C-terminal hydrophobic sequence of Bak is constitutively inserted into membranes and therefore cannot occupy the hydrophobic groove. However, the evidence that tBid binds to Bcl-XL and Bax similarly is controversial; data with Bax mutants indicates that the $\mathrm{BH} 3$ motif of tBid may interact with helix 1 of Bax rather than with the BH3 motif of Bax that is part of the hydrophobic groove [8].

The location and persistence of the binding of BH3-only activators to Bax and Bak is also debatable. Purified tBid pulled-down Bax synthesized by in vitro translation in the absence of detergent suggesting that the initial interaction can take place in cytoplasm [5]. However, we have shown that $\mathrm{tBid}$ causes the conformational change associated with Bax activation only in the presence of membrane, suggesting that to be effective the interaction between Bax and tBid must take place at the membrane [12]. Interestingly tBid is targeted to mitochondrial membrane efficiently via multiple internal helices (and in some cases additionally by a myristoylated $\mathrm{N}$-terminus) resulting in exposure of the $\mathrm{tBid}$ BH3 motif [22-26]. Moreover, a recent report indicated that a membrane-tethered Bid $\mathrm{BH} 3$ peptide is much more potent in activating Bax than the corresponding soluble peptide [27]. However, we did not detect any tBid bound to Bax oligomers after activation in mitochondria, suggesting most tBid dissociates from Bax after Bax inserts into the membrane [11]. Moreover, in a crosslinking study tBid-Bax hetero-adducts were not detected in the mitochondria when Bax homo-adducts were present [28]. Since Bak is constitutively inserted into mitochondrial membranes, its interaction with BH3-only and other activators must occur at the membrane. Thus tBid was co-immunoprecipitated with Bak in the mitochondrial membrane [15], but tBid was not crosslinked to Bak that was crosslinked with other Bak proteins. These results are consistent with a model in which tBid is released 
when either Bax or Bak homo-oligomerizes in the membrane as shown in Fig. 1. The precise sequence of binding and dissociation may differ between BH3-only activators, as co-immunoprecipitation of Bim with Bax in the heavy membrane fraction suggests that this complex persists in membrane [19]. The details of the interaction between Bim and Bak have not yet been investigated.

The direct activation model proposes that anti-apoptotic Bcl-2 family proteins inhibit Bax activation mainly by sequestration of the activator BH3-only proteins. Consistent with this feature of the model, purified Bcl-2, Bcl-XL, Mcl-1, $\mathrm{Bcl}-\mathrm{w}$ or Bfl-1/A1 protein bind to purified Bid and/or Bim proteins or their $\mathrm{BH} 3$ peptides in solution based assays [13,29]. Complexes between these anti-apoptotic proteins and BH3-only activators were also detected in isolated mitochondria or total cell lysates [3, 29, 30]. These interactions are functional when investigated in many contexts: in liposomes, mitochondria, or cells, the multi-BH domain anti-apoptotic proteins inhibited $\mathrm{tBid} / \mathrm{Bim}$ induced $\mathrm{Bax}$ or Bak activation events including insertion into membranes, oligomerization and permeabilization [1-3, 7, 9, 29].

As a consequence of the inhibition of $\mathrm{BH} 3$-only activators by anti-apoptotic proteins, other BH3-only proteins may act as sensitizers by displacing the activators from anti-apoptotic proteins, thus allowing the activators to bind to Bax/Bak. This group of anti-apoptotic proteins includes Bad, Bik, Bmf, Hrk, Bnip3, and Noxa. Consistent with this role, BH3 peptides from these sensitizers did not activate Bax or Bak in MOM liposomes or isolated mitochondria, and did not trigger cytochrome $c$ release or apoptosis in cells $[1-3,7]$. However, they did bind to anti-apoptotic Bcl-2 family proteins neutralizing them and releasing the inhibition of the activator $\mathrm{BH} 3$ peptides or proteins. As a consequence, the released activator $\mathrm{BH} 3$ sequences bound to Bax or Bak to trigger cytochrome $c$ release and apoptosis [1-3, 7]. A prediction is that the intact $\mathrm{BH} 3$-only sensitizer proteins may function similarly to their corresponding peptides, but reconstitution studies using purified full length BH3-only sensitizers have not yet been carried out.

In addition to activation by $\mathrm{BH} 3$-only pro-apoptotic proteins, previously activated Bax/Bak can also activate itself. This phenomenon, termed auto-activation, was first suggested by Ruffolo and Shore, who noted that an activated Bak mutant potently induced conformation change and oligomerization of non-activated Bak. They suggested that this mechanism may propagate the activation initiated by $\mathrm{BH} 3$-only proteins [31]. We recently showed auto-activation may also be relevant for Bax: an extended peptide including the BH3 motif and downstream residues of Bax can activate purified Bax when injected into cells and in both mitochondrion and a liposome based cell free systems. Further analyses showed that liposome-bound Bax activated soluble Bax suggesting that membrane binding causes a conformation change in Bax exposing the extended peptide. Therefore, membrane-bound Bax can activate cytosolic Bax in vitro [32]. However, we have not yet determined whether it is membrane-bound monomeric, oligomeric Bax or both that mediate auto-activation.

Cross-activation of Bax and Bak has also been observed. $\mathrm{Bak} \mathrm{BH} 3$ peptide triggered Bax conformation change in presence of mitochondria and caused membrane insertion [33]. Bak oligomerization was observed in Bax expressing cells after ATP depletion but not in Bax knockout cells, suggesting that in that system Bak activation requires Bax [34]. In contrast, Bax oligomerization occurred in the Bak knockout cells after the same treatment, suggesting that Bax can be activated independent of Bak. Bif-1 (a protein that is not a Bcl-2 family member; see Section 4.1) selectively binds to Bax but not Bak and may be required for Bax activation in some circumstances [35, 36]. In Bif-1 expressing cells both Bax and Bak were activated after drug treatment, and in Bif-1 deficient cells, both Bax and Bak activation were abolished, suggesting that in these cells Bak activation may require Bax activation [36].

Auto- and cross-activation of Bax and Bak are difficult to explain within the current version of the direct activation model, where apoptosis proceeds only when the capacity of anti-apoptotic proteins to "titrate out" activator BH3-only proteins has been exceeded. If this were the case, then no excess "free" anti-apoptotic proteins would be available to inhibit activated Bax and Bak, particularly when generated through auto- and cross-activation. This prediction was not supported by experiments showing that Bcl-2 inhibited the auto-activation of Bax and Bak [31, 32]. Furthermore, if Bcl2 and Bcl-XL must be inactivated by $\mathrm{BH} 3$-only proteins prior to activation of Bax or Bak and anti-apoptotic proteins cannot bind and inhibit Bax/Bak directly, then auto-activation would mean that any activation of Bax or Bak would ultimately kill the cell. One solution to this problem would be if Bax/Bak auto-activation was limited to oligomers in which oligomerization by $\mathrm{BH} 3$ proteins is self limiting. In this case apoptosis could still be regulated if the initiation of each oligomer required a $\mathrm{BH} 3$ activator.

Another prediction of the direct activation model is that most anti-apoptotic proteins are either unoccupied or bound by activator $\mathrm{BH} 3$-only proteins in non-stressed cells. This prediction was at odds with the data that Mcl-1 and Bcl-XL bound to Bak in dividing 293T cells [37], and that Mcl-1 formed a complex with Bax in 2B4 cells before treatment with dexamethasone [3]. However, it must be kept in mind that cells in culture are abnormal, stressed due to high oxygen, often transformed and usually growing on plastic therefore it would not be surprising if they are partially activated for apoptosis.

The direct activation model also proposes that the apoptosis inhibitors are in a stable complex with activator BH3- 
only proteins and that this is what allows non-apoptotic cells to survive. Stress-induced increases in sensitizer BH3-only proteins are required to displace the activators from the inhibitors. However, Bcl-w can be inactivated by integration into the mitochondrial membrane triggered by binding to $\mathrm{Bim}$, suggesting that Bim interaction with Bcl-w is dynamic and disabling, directly contrary to the prediction of the direct activation model [38]. We also found that tBid binds to Bcl-2 transiently; however, in this case, the binding activates Bcl-2 by changing its conformation. The tBid did not remain bound to conformationally altered Bcl-2 after activating it [11], again demonstrating that anti-apoptotic proteins do not function exclusively as passive "traps" for BH3 activators.

\section{Displacement model}

The main competing model to explain the regulation of apoptosis by Bcl-2 family members is displacement (or indirect activation): the salient feature is that the multi-BH proapoptotic proteins Bax and Bak are constitutively active and must be continuously bound and inhibited by multi-BH antiapoptotic proteins for cells to survive (Fig. 2). In apoptotic cells, BH3-only proteins displace Bax and Bak from antiapoptotic proteins such as Mcl-1 and Bcl-XL. Since Bax or Bak can be inhibited by more than one anti-apoptotic protein, all the relevant anti-apoptotic proteins must be inhibited for apoptosis to proceed. Furthermore, BH3-only proteins display selectivity for their targets, so more than one $\mathrm{BH} 3$-only protein may be required to inhibit all relevant anti-apoptotic proteins. The released Bax and Bak are active apoptosis inducers that oligomerize and permeabilize the mitochondrial membrane. As shown in Fig. 2, BH3 protein binding renders anti-apoptotic proteins non-functional by (a) displacing Bax or Bak (shown for Bcl-XL and Bax), (b) inducing a nonfunctional membrane integrated topology that can no longer bind Bax or Bak (shown for Bcl-w and Bim) or (c) enabling proteasome mediated degradation (shown for Mcl-1 and PUMA).

In support of the displacement model, complexes of Bak with various anti-apoptotic proteins are present in dividing cells in culture. Selectivity has been demonstrated by the fact that Bak in the membrane fraction can be coimmunoprecipitated with Mcl-1 and Bcl-XL but not Bcl-2, Bcl-w or A1 [37, 39, 40]. Consistent with this, a Bak BH3 peptide has high affinity for purified Mcl-1 and Bcl-XL proteins but low affinity for Bcl-w and $\mathrm{Bcl}-2$ when measured in

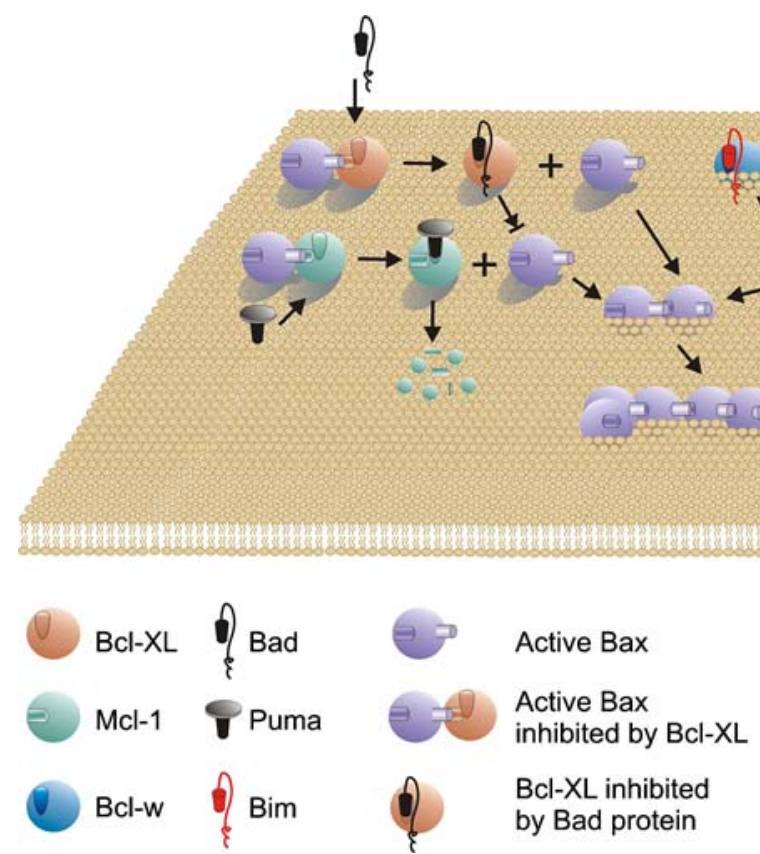

Fig. 2 The displacement model. Anti-apoptosis proteins such as Bcl$\mathrm{XL}, \mathrm{Mcl}-1$ and Bcl-w (brown, green and blue, respectively) bind to and thereby inhibit active forms of Bax/Bak (powder blue; for clarity only Bax is shown; in this model Bax and Bak are assumed to function similarly). $\mathrm{BH} 3$ only proteins (black or red, as indicated in the legend below the diagram) initiate membrane permeabilization by displacing active Bax from the anti-apoptosis proteins by direct binding to antiapoptosis proteins. The active Bax then inserts into the membrane and oligomerizes (the order is not specified by the model and was selected arbitrarily). Binding of $\mathrm{BH} 3$ proteins inhibit anti-apoptosis proteins by various mechanisms: Bcl-XL by sequestration, Bcl-w by embedding it in the membrane and Mcl-1 by initiating degradation. For simplicity each $\mathrm{BH} 3$ protein is shown binding a single anti-apoptosis protein however, the model proposes hierarchies of interaction based on the relative affinities of the interactions. Moreover, an active Bax displaced from one anti-apoptosis protein may be bound by a different anti-apoptotic Bcl-2 family member. Therefore, initiating membrane permeabilization requires inactivating all of the relevant anti-apoptosis proteins. For simplicity the legend includes only one example of each inhibitory process (Bcl-XL inhibition of Bax and Bad inhibition of Bcl-XL) 
vitro using the Biacore system [37]. A mutation in the BH3 motif of Bak that reduced the binding affinity of the peptide to Mcl-1 abolished Bak-Mcl-1 co-immunoprecipitation in cell lysate, suggesting that the $\mathrm{BH} 3$ motif of Bak is required for the binding with the anti-apoptotic partner [37]. Bak has also been proposed to be held in check by other binding partners such as VDAC2 [41]. However, the stoichiometry of the interaction and the relative amounts of the endogenous proteins in cells has not been reported. Therefore, it is difficult to assess the physiological relevance of Bak binding partners.

The status of Bax as a constitutively active protein that must be inhibited for cell survival is less clear. The original identification of Bax as membrane bound protein that binds to Bcl-2 in non-stressed cells [42] is an artifact of the detergent used for cell lysis, as non-ionic detergents induce an activated conformation of Bax [43]. In fact Bax behaves as a monomeric protein after cell solubilization with CHAPS, a detergent that does not alter Bax conformation or authentic binding interactions [44, 45]. However, even using these detergent conditions discordant results have been obtained: Bax was not co-immunoprecipitated with Mcl-1 and Bcl$\mathrm{XL}$ in one report [37], but was co-immunoprecipitated with Mcl-1 by another group [3]. The latter results are difficult to reconcile with cell fractionation data from many laboratories indicating that Bax is either primarily cytosolic or loosely bound to membranes. Moreover, crosslinking studies are also consistent with Bax being primarily monomeric in dividing cells [45]. Thus, it is difficult to see how a monomeric soluble protein is being 'held in check' by binding to anti-apoptotic proteins. If most Bax is not being held in check, then presumably it must be activated somehow prior to integrating into membranes and oligomerizing.

The second critical feature of the displacement model is that $\mathrm{BH} 3$ only proteins disrupt the interaction between multi-domain pro-apoptotic and anti-apoptotic proteins. The displacement of Bax from anti-apoptotic proteins was documented even before the displacement model was formally proposed. Bad was initially identified as a protein that competes with Bax for binding to Bcl-XL [46]. The displacement model also explains how insertion of Bax into mitochondrial membranes by a Bad BH3 peptide occurs in the presence of $\mathrm{Bcl}-\mathrm{XL}$ or Bcl-2. However, the Bad BH3 peptide does not cause Bax to insert into membranes in the absence of prior binding to an anti-apoptotic protein [5]. Thus, it may be that Bad contributed to signal integration by functioning to augment a prior signal that activated Bax but the activated Bax was then inhibited by $\mathrm{Bcl}-\mathrm{XL}$ or $\mathrm{Bcl}-2$. In this regard it is often difficult to ascertain just how healthy the cultured cells used in most of these experiments are (see above). Moreover, the use of transformed cells which may be more dependent on anti-apoptosis proteins for continued survival may also affect the results obtained [1].
Bak has also been shown to be activated after displacement: in cells that overexpress Noxa, binding of Mcl-1 to Bak is reduced as Mcl-1-Noxa complexes form [37]. Here Noxa displaces Bak from Mcl-1 by direct binding since a Noxa mutant that does not bind to Mcl-1 does not displace Bak. However, since Noxa does not bind to Bcl-XL, the released Bak can still be bound and inhibited by Bcl-XL, if present. As predicted, in cells expressing both Mcl-1 and $\mathrm{Bcl}-\mathrm{XL}$, apoptosis is not induced by overexpression of Noxa alone. However, when Noxa was co-expressed with an engineered BH3-only protein that binds to Bcl-XL, apoptosis was induced. Knocking out Bcl-XL also sensitizes these cells to Noxa killing. In contrast, loss of Bcl-2 had no effect on Noxa killing, consistent with the finding that Bcl-2 did not sequester Bak in these cultured cells. These data indicate that all the relevant anti-apoptotic proteins that engage the multi-BH pro-apoptotic protein must be neutralized before apoptosis can take place. However, which anti-apoptotic protein is relevant may differ according to the cellular context, as Bcl-2 binds to and inhibits Bid induced activation of Bak in mitochondria from human epithelial KB cells [31]. In adenovirus E1A infected cells Bak released from Mcl-1 forms a complex with E1B 19K, a viral Bcl-2 homolog [39]. Thus, the conclusion that Bcl-2 does not sequester activated Bak cannot be generalized at this moment.

Binding of anti-apoptosis proteins by their BH3-only ligands inactivates the anti-apoptotic proteins by multiple mechanisms. Noxa binding to Mcl-1 not only displaced Bak from, but also induced Mcl-1 degradation [37] dependent on proteasome activity [48]. The E3 ubiquitin ligase, Mule/ARF-BP1, catalyzes the polyubiquitination of Mcl-1 [49]. This enzyme contains a BH3 motif that binds to Mcl-1 but not to Bcl-XL or Bcl-2. This specificity accounts for the rapid turnover of Mcl-1 compared to other anti-apoptotic proteins. However, the exact sequence of these competitive binding events is not known. Does Noxa bind to Mcl-1 first to displace Bak and then Mule bind to Mcl-1 to displace Noxa? Interestingly, binding of the Bim BH3 peptide prevented Mcl-1 binding to Mule and Mcl-1 subsequent degradation, suggesting that Mule may not be able to compete with all BH3-only proteins for Mcl-1 [50]. Perhaps Mule only displaces sensitizer $\mathrm{BH} 3$-only proteins like Noxa that bind Mcl-1 more weakly than activator $\mathrm{BH} 3$ proteins like $\mathrm{Bim}$, as indicated by the relative affinities of the respective BH3 peptides [2, 3, 29]. However, if sensitizers bind Mcl1 with lower affinity than activator proteins then very high levels of expression of the sensitizer might be required to be effective. These data suggest that a hybrid of the displacement model ("Bak becomes active after Mcl-1 disappears") and the direct activation model ("activator and sensitizer proteins both kill the cell, but require different mechanisms") best explains certain results. 
In contrast to the consequence of Mcl-1 displacement, binding of Bcl-XL by Bad did not cause Bcl-XL degradation, but rather migration to and insertion into the mitochondrial membrane. It is not clear if Bad remains bound to Bcl-XL in this membrane integrated conformation to prevent $\mathrm{Bcl}-\mathrm{XL}$ from binding to Bax or Bak [51]. Translocation of Bcl-XL to mitochondria was also observed after UV induced apoptosis, but only after Mcl-1 was degraded [48]. Perhaps in this case, the relevant $\mathrm{BH} 3$ protein binds more tightly to Mcl-1 first, initiating Mule-dependent degradation. After Mule has displaced the $\mathrm{BH} 3$ protein from $\mathrm{Mcl}-1$, the $\mathrm{BH} 3$ protein is free to bind to Bcl-XL. Similar to the induced membrane translocation of Bcl-XL by Bad, binding of Bim to Bcl-w induced Bcl-w insertion into the mitochondrial membrane, with neutralization of the anti-apoptosis activity [38]. However, in this experiment, Bim was tethered to Bcl-w and thus could not diffuse away; it is unclear if a Bim protein free to dissociate from Bcl-w would provide ongoing inactivation of Bcl-w.

Whatever mechanism leads to inactivation of the antiapoptotic proteins, co-immunoprecipitation experiments with a series of $\mathrm{BH} 3$-only proteins demonstrated that specific BH3-only proteins have different anti-apoptotic proteins as preferred targets [29, 52]. For examples, Bad bound to both Bcl-2 and Bcl-XL but not to Mcl-1; Bik bound strongly to Bcl-XL but not to Bcl-2 or Mcl-1; and Noxa only bound to Mcl-1 not to Bcl-2 or Bcl-XL. The exceptions were Bim and Puma that bound to all three anti-apoptotic proteins. Selective targeting of anti-apoptosis proteins by $\mathrm{BH}$-only proteins was also seen in binding studies using specific $\mathrm{BH} 3$ peptides [2, 3, 29]. Therefore, Bim or Puma should neutralize all of the anti-apoptotic proteins and hence be the most effective apoptosis inducers, whereas Bad or Noxa would be partial inducers since each neutralizes only a subset of the anti-apoptotic proteins. These predictions were in fact confirmed by experiments in cells where multiple anti-apoptotic proteins are expressed [29].

Interestingly a combination of Noxa and an engineered protein with the $\mathrm{Bad} \mathrm{BH} 3$ motif induced apoptosis as effectively as Bim alone, suggesting that partial inducers with different binding spectra cooperate to neutralize all anti-apoptotic proteins [29]. However, the combination of Noxa and Bad BH3 peptides did not induce cytochrome $c$ release from mitochondria isolated from wt or Bcl-2expressing FL5.12 cells grown in the presence of IL-3 [3]. These data suggest that binding of all anti-apoptotic proteins is not sufficient per se to induce apoptosis in all contexts. Presumably these non-apoptotic cells did not contain activated Bak or Bax as required by the displacement model. Instead, the results are more consistent with the direct activation model whereby the Bax/Bak released from binding to $\mathrm{Bcl}-2$ by Noxa and Bad still requires activation by $\mathrm{BH} 3$-only activators.
Another prediction of the displacement model is that reducing the binding affinity of a BH3-only protein for its anti-apoptotic targets will release less activated Bax or Bak and result in less apoptosis. However, a Bid mutant (mIII-1) with reduced binding affinity for Bcl-2 and Bcl-XL is as effective as the wild type Bid in mitochondrial and liposomal permeabilization assays $[13,27]$. Furthermore, a Bid mutant (mIII-3) that retained wild type binding affinity for Bcl2/Bcl-XL but had reduced affinity for Bax showed impaired pro-apoptotic function in these in vitro assays. Moreover, neither mutant counteracted the protection by Bcl-2 in FL5.12 cells following IL-3 withdrawal [52]. These results can be most easily explained if two activities of Bid are jointly necessary; binding to Bax activates Bax, while binding to $\mathrm{Bcl}-2$ prevents Bcl-2 from inhibiting activated Bax. Thus, in the experiments described above Bid-mIII-1 bound to Bax activating it, but did not bind to $\mathrm{Bcl}-2$ to prevent inhibition of Bax, whereas Bid-mIII-3 did not activate Bax because of low binding affinity. In this last case, directly contrary to the prediction of the displacement model, Bid-mIII-3 binding to Bcl-2 did not induce apoptosis [13, 52]. Consistent with this view, we recently demonstrated that Bax mediated liposome permeabilization induced by tBid-mIII-1 was inhibited by membrane-tethered Bcl-2 [53].

Thus detailed examination of the two competing models informs us that each accounts for some, but not all of the experimental results. Some of the discrepancies are due to different assays and cell lines that are used. In this context, the experiments with mitochondria from either normal hematopoeitic cells or their leukemic counterparts are informative [1, 3]: Bax/Bak mediated cytochrome $c$ release by $\mathrm{BH} 3$ only peptides from the former follows the direct activation model, whereas the displacement model best explains the latter.

Ultimately, the decision to "make a hole" is dependent on conformational changes in Bax and Bak that are controlled by multiple competing factors that have different affinities and concentrations to determine the outcome of the regulatory interactions with these pore-forming proteins. Furthermore, the concentrations, affinities and conformations of the regulatory proteins themselves differ by subcellular localization. We therefore propose a model which we term "embedding together" that incorporates these features.

\section{Embedding together}

The main distinguishing feature of the embedding together model is the recognition that membrane permeabilization does not occur until Bax and/or Bak insert multiple sequences into the MOM lipid bilayer. Therefore, the final and essential stage at which membrane permeabilization is regulated takes place in the bilayer. Furthermore, be- 
cause large conformational changes accompany insertion into membranes, measurements of protein-protein interactions must be assessed in this environment for these binding interactions to be relevant to the final regulated stage of MOMP. Although both direct activation and displacement models accept that there are multiple interactions between anti- and pro-apoptotic proteins, and the proponents of each have measured the affinities of many of these interactions in vitro $[1,37]$, all these measurements are made with either peptides or proteins in solution, or with truncated proteins binding to peptides chemically coupled to artificial surfaces. These quantitative approaches are useful and can suggest, but not confirm, physiologically relevant interactions. The affinity and on/off rates for these interactions may differ significantly when proteins are full length, in their correct membrane topology, and different conformations ensue. In cells and tissues, support for direct activation and displacement models has been limited to co-immunoprecipitations, in many cases with over-expressed proteins. There are many important protein:protein interactions in which the binding affinity is too low to survive co-precipitation. To accurately predict the biological importance of competing interactions measured in vitro requires determining binding constants with full length proteins in the right context, in solution and on membranes, where appropriate. For example, for tBid interactions with Bax measurements must be made in solution and for proteins bound to membranes because both proteins are found in cytoplasmic and membrane bound forms. However, Bcl-2 and Bak are constitutively bound to membranes therefore binding interactions should be measured in or on

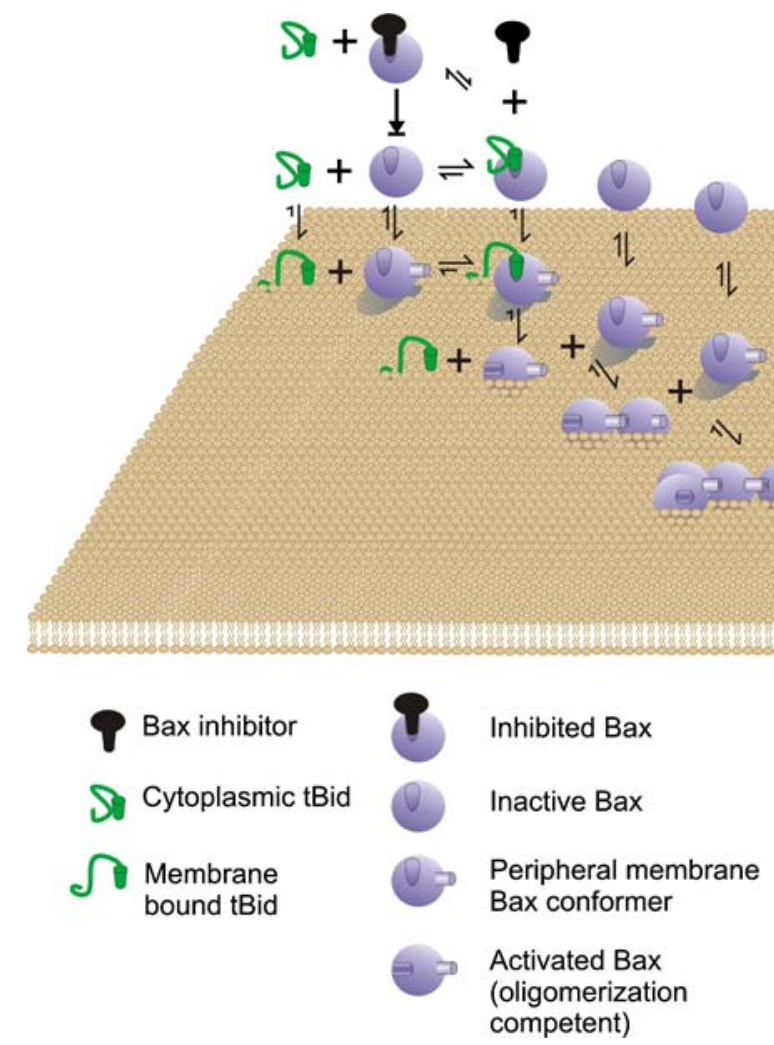

Fig. 3 The embedding together model-Initiation of membrane permeabilization. Bax is most frequently an inactive cytoplasmic protein. The binding affinity for cytoplasmic Bax (powder blue) for cytoplasmic BH3 proteins (tBid is shown) is low and cytoplasmic Bax is in equilibrium with a form that binds with relatively low affinity to the surface of membranes. Therefore, a relatively low affinity inhibitor (black) that might not remain bound during immunoprecipitation can inhibit Bax in the cytoplasm by shifting the equilibrium away from membrane binding. Bax binds to membranes peripherally concomitant with a conformational change in Bax that increases the affinity of a $\mathrm{Bax} / \mathrm{tBid}$ interaction. In the diagram tBid (green) is the only activator shown however, the model presupposes $\mathrm{BH} 3$ only proteins and other proteins that interact with Bax both in the cytoplasm and on the membrane can modulate one or more of the equilibriums shown. In the case of tBid the affinity for membranes is high and binding to mem- branes results in a conformation change that increases tBid affinity for Bax. The interaction between membrane bound tBid with peripherally membrane bound Bax triggers insertion of Bax into the membrane. The integral membrane form of Bax can recruit additional Bax proteins and oligomerize to permeabilize the outer mitochondrial membrane. The only step in Bax activation that is effectively irreversible is integration into the membrane. The model does not require that any one pro-apoptotic protein performs all of the functions ascribed to tBid, but rather envisions that most will perform only a subset of them. Bak is proposed to function similarly to Bax except that it is expected to bind the different modulators (e.g. tBid, Bim) with different affinities and its inactive conformation is constitutively membrane bound and is thus envisioned to be functionally similar to the peripheral membrane form of Bax 


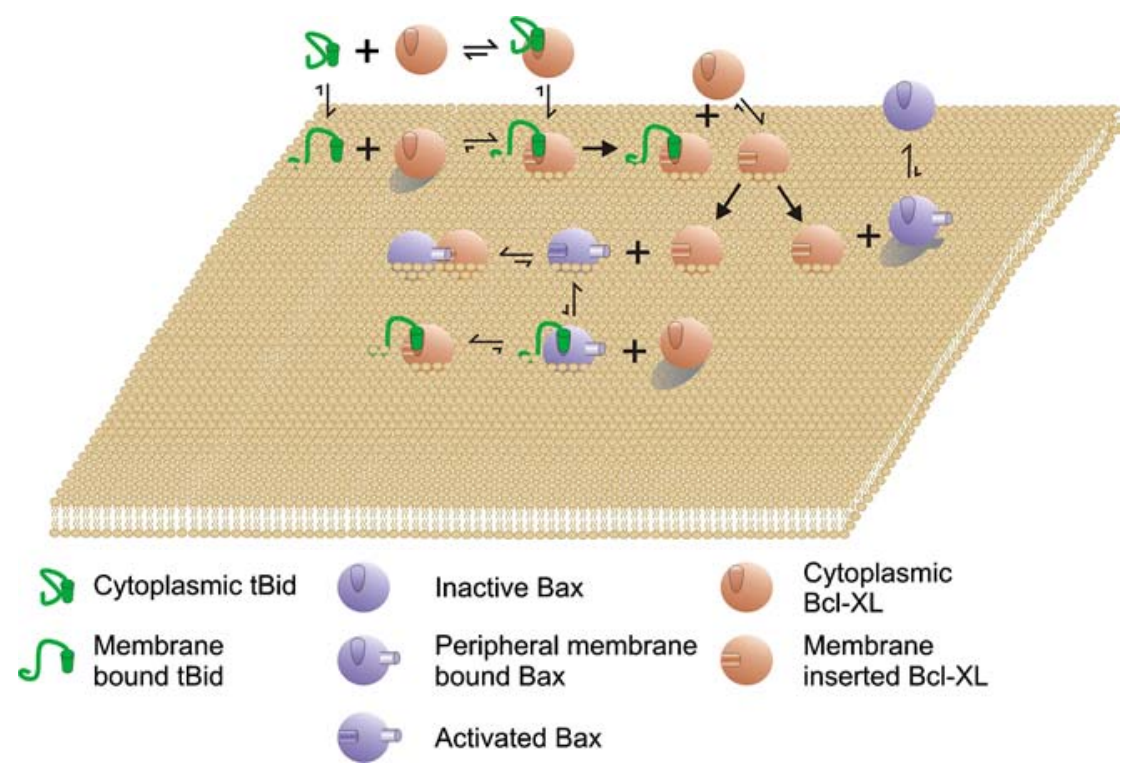

Fig. 4 The embedding together model-Inhibition of membrane permeabilization. Bcl-XL (Brown) inhibits both tBid (green) and Bax (powder blue). Although it may bind to both the membrane bound and cytoplasmic forms of $\mathrm{tBid}$, the affinity of $\mathrm{Bcl}-\mathrm{XL}$ for membrane bound tBid is higher. Binding of $\mathrm{Bcl}-\mathrm{XL}$ to tBid tiggers insertion of $\mathrm{Bcl}-\mathrm{XL}$ into membranes. Once inserted in membranes either Bcl-XL recruits other $\mathrm{Bcl}-\mathrm{XL}$ proteins to insert into membranes, or tBid dissociates and recruits additional $\mathrm{Bcl}-\mathrm{XL}$ proteins. $\mathrm{Bcl}-\mathrm{XL} / \mathrm{tBid}$ complexes are otherwise dead-end structures that neither prevent nor promote apoptosis. However, because the affinity of Bcl-XL for tBid is higher than that between Bax and $\mathrm{tBid}$, interactions between $\mathrm{tBid}$ and Bcl-XL inhibits Bax recruitment to the membrane. Membrane bound Bcl-XL further prevents Bax inserting into the membrane by preventing the conformation change in Bax that occurs at the membrane. Membrane bound Bcl-

membranes. The embedding together model includes interactions in solution and on membranes as multiple parallel equilibriums in which the relative affinities and rate constants dictate the most likely sequence of events (Figs. 3 and 4).

\subsection{Regulation of Bax and Bak in membranes}

In the embedding together model, we propose that Bax and Bak go through multiple, regulated conformational changes before assuming a final conformation (and/or stoichiometry, as discussed below) necessary for membrane permeabilization. This conclusion is based on disparate observations from many laboratories exploring different model systems. We demonstrated that when Bax interacts with a membrane surface even without inserting into the membrane it undergoes a transient change in conformation that increases its thermal stability (measured by differential scanning calorimetry) and exposes an amino-terminal epitope (bound by the 6A7 monoclonal antibody [54]) [12]. Upon re-isolation Bax reverts to the 6A7 negative conformation, suggesting the two conformers of Bax are in a dynamic equilibrium and that interaction with the membrane surface shifts the equilibrium towards
$\mathrm{XL}$ also binds to and inhibits the integral membrane (oligomerization competent) form of Bax. The only step that is effectively irreversible for Bcl-XL is integration into the membrane. The model does not require that any one anti-apoptotic protein performs all of the functions ascribed to $\mathrm{Bcl}-\mathrm{XL}$, but rather envisions that most will perform only a subset of them. Bcl-2 is proposed to function similarly to Bcl-XL except that it is expected to bind different pro-apoptotic proteins (e.g. tBid/Bax) with different affinities. As Bcl-XL competes with Bax/Bak in all steps it has no inactive conformation. Moreover, pro-apoptotic and anti-apoptotic multi-region Bcl-2 family proteins are envisioned as functioning similarly (competitively) except that the anti-apoptotic proteins are unable to support oligomerization and therefore, function as defective constituents of Bax/Bak oligomers inhibiting further oligomerization and membrane permeabilization

the $6 \mathrm{~A} 7$ positive conformer sufficiently that it can be trapped by interaction with the antibody [12]. Similarly the $6 \mathrm{~A} 7$ positive conformer is in equilibrium with a conformer that can insert into membranes but the equilibrium strongly favours the cytoplasmic form (Fig. 3). A further interaction with a BH3 molecule like tBid, a specific lipid in the membrane or interaction with another activator (see below) can shift this equilibrium in favour of the conformer that then inserts into membranes. Insertion into membranes is irreversible and another interaction may or may not be required to then "lock in" the $6 \mathrm{~A} 7+$ conformation. The pro-apoptotic arm of the pathway is illustrated for tBid and Bax not to limit it to these proteins but because these proteins have proven to be more experimentally tractable and therefore there is more experimental evidence to draw upon (Fig. 3).

Recently, we demonstrated that when myc $-/$ - cells were exposed to apoptotic stimuli, Bax adopted a membrane topology in which both the alpha-5/6 helices and the alpha- 9 carboxyl-terminal tail-anchor inserted into membranes. In this conformation, Bax is in a low molecular weight complex that does not form pores in membranes. The basic topology of this membrane embedded conformation is the same that 
Bax adapts in its pore forming conformation in myc $+/+$ cells [10]. However, in myc $-/-$ mitochondrial membranes, Bax does not bind to the $6 \mathrm{~A} 7$ monoclonal, and thus a myc regulated activity is required for this "activating" conformational change. Together these results strongly suggest that Bax undergoes two independent conformation changes (insertion into membranes, exposure of the $6 \mathrm{~A} 7$ epitope) prior to oligomerization and permeabilization of membranes. These changes may occur in either order and each is likely to change the affinity of Bax for the different molecules that regulate membrane permeabilization. The embedding together model does not limit the interactions that regulate membrane permeabilization to $\mathrm{Bcl}-2$ family proteins.

Consistent with this view, the action of an intracellular isoform of clusterin also indicates that there are multiple points where membrane-bound Bax conformation is regulated [55]. Clusterin binds specifically to $6 \mathrm{~A} 7$ positive Bax and inhibits subsequent oligomerization. Thus in one of the possible simplified linear sequences of changes in Bax, translocation leads to integration which leads to a second conformational change which leads to oligomerization. The myc dependent factor is required for going from the second to the third step, and clusterin inhibits the transition between third and fourth states. However, because the embedding together model assumes multiple dynamic equilibriums, changes at any step propagate to the others. As a consequence, decreasing clusterin expression by silencing RNA enhances spontaneous apoptosis, and over expressing clusterin decreases apoptosis. Clusterin does not inhibit apoptosis in Bax $-/-$ cells or apoptosis mediated by Bak [55]. Significantly in an animal model of myc induced tumorigenesis, over expression of clusterin enhances tumor formation, indicating that in the context of a cell expressing deregulated myc with no other exogenous apoptotic stimuli, Bax may exist in a myc-regulated partially activated state that sensitizes cells to apoptosis. Inhibition of this sensitization by clusterin therefore enhances myc mediated transformation.

Recently, other non-Bcl-2 family membrane bound proteins have been reported to regulate Bax activation positively. Bif-1/endophilin B protein has a cytoplasmic and partly mitochondrial constitutive distribution and interacts with Bax via its amino terminal domain [56]. During apoptosis, Bif-1 forms homodimers in the cytoplasm, and migrates to mitochondria [36]. The interacting domain on Bax was not identified, but Bax bound to Bif-1 was not co-immunoprecipitated with $6 \mathrm{~A} 7$, indicating the possibility of competing binding sites. Over-expression of Bif-1 increased membrane translocation and activation of Bax, but had no affect on the constitutive translocation of the $\Delta S 184$ mutation of Bax suggesting a role for Bif-1 in recruiting Bax to MOM. Knockdown of Bif-1 decreased Bax 6A7 conformational change and migration of Bax to mitochondria after exposure to chemotherapy. Finally, embryonic fibroblasts from Bif-1 -/- mice had greatly delayed apoptosis. Thus Bif-1 seems to act early in the series of conformational changes that enable the migration and activation of Bax. In contrast, several other cytoplasmic proteins have been identified that bind to the $\mathrm{C}$ - and/or $\mathrm{N}$-terminus of Bax to function as a clamp, preventing Bax activation and apoptosis [57].

Two other factors seem to enhance later steps in the pathway. MAP-1 was found in a yeast two-hybrid screen for Bax interacting proteins [58]. It has a degenerate 8 amino acid $\mathrm{BH} 3$ like region required for interaction with $\mathrm{Bax}, \mathrm{Bcl}-2$ and Bcl-XL. In cell lines, Bax only interacted with MAP-1 after induction of apoptosis (in assays in which CHAPS was used to lyse cells). When NP-40 was used, apoptosis induction was not necessary but NP-40 changes Bax and may also change MAP-1 conformation to a more apoptotic one [58]. Decreasing MAP-1 expression by silencing RNA in MCF7 cells leads to decreased apoptosis induced by multiple stimuli [59], and was associated with less conformationally changed and membrane-bound Bax. This suggests that the role of MAP-1 is to shift the equilibrium of Bax conformers sufficiently to "lock in" the 6A7 conformational change after it has been induced by an activator molecule.

Apoptosis associated speck-like protein (ASC) is a p53 regulated protein [60] that binds to Bax constitutively in the cytoplasm of untreated cells, but is localized to mitochondria and can be co-immunoprecipitated by $6 \mathrm{~A} 7$ after induction of apoptosis. Decreasing ASC expression by silencing RNA decreased Bax migration and the 6A7 conformational change after apoptosis, suggesting ASC and MAP-1 function similarly.

Traditionally p53 has been recognized to affect apoptosis by acting as a transcription factor with many target genes that regulate apoptosis. However, recent data from several groups has indicated that $\mathrm{p} 53$ has an additional and possibly direct role in regulating mitochondrial physiology relevant to apoptosis by directly interacting with Bcl-2 family members that mediate MOMP.

The first evidence of this direct role was suggested by a report that a fraction of p53 localizes to the mitochondria in tumour cell lines undergoing p53 dependent apoptosis. The relevance of mitochondrial localization was supported by a report that the increased apoptotic activity of a natural polymorphic variant of p53 was due to increased nuclear export and mitochondrial localization [61]. The equivalent transcriptional activation properties of the two variants indicated a clear disassociation between apoptotic and transcriptional activity. Another naturally occurring mutation in p53 underscores the separability of these functions even more dramatically: the L25Q/W26S mutant is transcriptionally inactive, localized to the nucleus and does not mediate apoptosis. However, when this mutant was retained in the cytoplasm by blocking nuclear import, it localized to the mitochondria and mediated apoptosis [62]. 
There is controversy as to the direct target of p53 at mitochondria. Leu et al. [40] reported co-immunoprecipitation of p53 with endogenous Bak but not Bax (nor Bcl-XL as noted below), interaction of $\mathrm{p} 53$ synthesized by in vitro translation with Bak not Bax (nor Bcl-XL) and binding of recombinant GST- p53 to Bak synthesized by in vitro translation [63]. Finally, addition of p53 to enriched mitochondria caused oligomerization of Bak and release of cytochrome $c$ from Bak $+/+$ mitochondria but cytochrome $c$ was not released from Bak $-/-$ mitochondria. By contrast Chipuk et al. [62] demonstrated that isolated cellular p53 or recombinant p53 activated recombinant Bax to release cytochrome $c$ from mitochondria enriched cellular fractions [62]. A Bax requirement for the p53 activity in the mitochondria is at odds with the result from Leu et al. since the mitochondria from mouse liver contain Bak [64]. Furthermore p53 caused oligomerization of Bax in liposomes (as detected by BMH cross linking) and permeabilized liposomes. Despite this demonstrated function of p53 to activate Bax in highly purified systems, no direct interaction between Bax and p53 was detected by coimmunoprecipitation. These seemingly disparate results may be partly explained by different cellular sources of mitochondria in which either Bak or Bax are dominant (e.g. hepatic vs. fibroblast mitochondria) and the fact that post translational modifications of p53 such as mono-ubiquitination [61] and phosphorylation [65] may allow p53 to bind differentially to Bax, Bak or Bcl-XL.

Thus, the recent identification of multiple mitochondria associated $\mathrm{BH} 3$ and non- $\mathrm{BH} 3$ proteins that bind to and enhance the activation of Bax is congruent with membrane binding being an important step in the regulation of Bax. Consistent with this hypothesis, while Bax and tBid can permeabilize liposomes with no other components necessary, a trypsin sensitive factor promotes cytochrome $c$ release from mitochondria [66].

Finally, experiments with viral suppressors of apoptosis also indicate that there are multiple stages at which Bax conformational changes can be regulated. The cytomegalovirus product vMIA is an inhibitor of apoptosis that constitutively localizes to the outer mitochondrial membrane [67] where it regulates both mitochondrial bioenergetics [68] and prevents mitochondrial outer membrane permeabilization by Bax [69]. Paradoxically, this happens after vMIA recruits Bax from the cytosol to mitochondria causing full membrane insertion as well as the preliminary steps of oligomerization [68]. Furthermore, mitochondrial vMIA was able to mediate the membrane translocation of the Bax $\Delta 1-37 \mathrm{mu}-$ tant that does not otherwise translocate to mitochondria after apoptotic stress. It appears that vMIA sequesters Bax and prevents permeabilization at the mitochondrial membrane after it induces insertion and oligomerization of the protein. The sequestered Bax cannot be activated by tBid or other apoptotic stimuli again suggesting that that there are multi- ple regulated conformational changes during Bax activation. The surprising aspect of the vMIA mechanism of action is that it apparently enhances two early steps, but inhibits the final step.

There is also evidence that Bak undergoes multiple conformational changes during activation. Both endogenous and viral proteins have been identified that inhibit Bak activation. The second isoform of the voltage dependent anion ion channel (VDAC-2) binds constitutively to Bak in outer mitochondrial membranes [41]. VDAC-2 over expression prevented the oligomerization and spontaneous conformational change in Bak. As expected, the absence of VDAC-2 in embryonic fibroblasts rendered them more susceptible to apoptosis. Presumably VDAC- 2 competes with tBid and other $\mathrm{BH} 3$ protein(s) for the $\mathrm{BH} 3$ binding domain of Bak as VDAC-2 releases Bak if tBid is present. Moreover, a tBid mutant that does not bind to Bak does not release Bak from VDAC-2, suggesting that $\mathrm{tBid}$ interacts directly with Bak instead of VDAC-2. Bak bound to VDAC-2 may be in an inactive conformation since lysis of cells with NP40 (expected to activate Bak) but not CHAPS reduced the co-immunoprecipitation of Bak with VDAC-2 [41].

In the absence of VDAC-2, a portion of Bak undergoes a conformational change detected by altered protease sensitivity. However, this change was not detectable by BMH cross-linking, and only a fraction of the Bak oligomerizes into larger complexes. This suggests that full activation of Bak requires additional conformational changes, and that VDAC-2 inhibits a step prior to oligomerization. It also suggests that VDAC-2 'restrains' only a small fraction of the Bak in the cell, a result inconsistent with the displacement model.

Similar to Bax, viral inhibitors of apoptosis have been identified that bind to Bak. The vaccinia F1L protein suppresses apoptosis during viral infection and coimmunoprecipitates in cells with Bak, but not Bax, Bcl2, Bcl-XL or Mcl-1 [70, 71]. In mitochondria derived from mouse embryonic fibroblasts F1L prevented the tBID induced conformational change as detected by an epitope-specific monoclonal antibody, Bak oligerimization, crosslinking of Bak by BMH, and release of cytochrome $c$. In Jurkat and HeLa cells there is a small fraction of Bak that is oligomerized without any distinct apoptotic stimulus. However, it is unclear how 'normal' or 'healthy' these cells are as transformation makes cells 'addicted' to inhibitors of apoptosis. Expression of F1L protein did not noticeably decrease this "pre-activated" fraction. Thus F1L appears to inhibit Bak by sequestration in normal cells. In this sense, F1L forms a dead-end complex with "incompletely" activated Bak in membranes, similar to vMIA that forms a dead-end complex with Bax in membranes.

Taken together, these studies show that there are multiple conformations of Bax and Bak, and several endogenous and 
viral proteins have different affinities for these states. Unlike the direct activation and displacement models, the embedding together model would expect multiple conformational states that could be regulated by factors that would either enhance or retard these transitions.

\subsection{Bcl-2 family protein interactions lead to 'activation'}

Another feature of the embedding together model is based on the observation that, although composed of distinct sequences, many of the Bcl-2 family proteins are similar structurally. Therefore, we predict that they form similar (although not identical) structures in membranes and that the structural consequences of interactions between Bcl-2 family proteins have more in common than implied by either the direct activation or displacement models. We suggest that binding with BH3-only proteins does not simply displace binding interactions with either other $\mathrm{BH} 3$ proteins or activated Bax/Bak. Based on our data, we postulate that $\mathrm{BH} 3$ proteins cause conformational changes that can activate both pro- and antiapoptotic multi-domain Bcl-2 family members. Thus, we have reported that when tBid binds to Bcl-2 in mitochondria it causes a conformational change such that Bcl-2 helices 5 and 6 which are normally cytoplasmic become embedded in the membrane [72]. This conformational change appears necessary for at least a subset of anti-apoptotic Bcl-2 functions because for several Bcl-2 mutants embedding of helix 5 in the membrane is strongly correlated with prevention of apoptosis in vivo [11] and in vitro [11,32]. However, there was no correlation between Bax binding in solution and prevention of apoptosis. Persistent binding of tBid to the conformationally altered, functional wild type $\mathrm{Bcl}-2$, was not observed consistent with the "kiss and run" model proposed for Bax activation by tBid [73]. Thus it is possible that for both Bcl-2 and Bax, embedding in the membrane changes the conformation of the proteins thereby reducing the affinity for $\mathrm{BH} 3$ protein binding and shifting the equilibrium towards releasing tBid. The "vacant" binding site on Bcl-2 may now be ready to bind to Bax or Bak. A further prediction of our model is that the affinity of Bcl-2 for Bax (and other BH3 containing proteins) differ if measured in the "pre-activated conformation" in solution and without the complete carboxyl-terminal insertion sequence $[1,37]$ compared to the physiologic, activated conformation in membranes.

In contrast to our results with tBid (and Bim peptide), Bad peptide has been reported to cause the insertion and integration of Bcl-XL into mitochondrial membranes concomitant with inactivation of Bcl-XL. However, in these experiments there is generally a large excess of peptide. Therefore, it will be important to examine the effects of the binding of $\mathrm{BH} 3$ proteins to multiple anti-apoptotic proteins using full length proteins in a simplified in vitro system to further examine the relationship between conformation and function.

According to the embedding together model the induced conformational change that accompanies integration of helices 5-6 into membranes allows Bcl-2/XL to bind to membrane embedded Bax/Bak monomers/dimers, preventing further oligomerization of Bax/Bak (Fig. 4). These antiapoptotic proteins themselves do not form large oligomers in membranes in the activated conformation. Thus Bcl-2 and presumably $\mathrm{Bcl}-\mathrm{XL}$ act as oligomerization defective forms of $\mathrm{Bax} / \mathrm{Bak}$. In this context, it is interesting to note that activated Bcl-2/Bcl-XL and Bax all insert parts of helix 5, 6 and 9 into the membrane, are all initially found as monomers or dimers in the membrane [10,51], and can form ion conducting channels in artificial lipid bilayers that requires the alpha 5-6 helices [74]. However, when the pore size is assayed with larger molecules, the pores formed by Bcl-XL are considerably smaller than those formed by large Bax oligomers (Lin et al., in preparation) [53]. This suggests a simple physical model whereby the oligomerized proteins form the borders of an aqueous channel in the lipid bilayer, and the channel size is a function of the number of monomers in the channel wall. Precise measurement of the stoichiometry of Bax oligomers is therefore required to understand the structure of this pore.

We hypothesize that the conformational change that leads to large detergent resistant oligomer formation by Bax/Bak is due to domain swapping, perhaps of alpha 5-6 helices among adjacent monomers. Accordingly, the anti-apoptotic proteins cannot mediate large pore formation because the conformational changes these proteins undergo in membranes are sufficiently different. Mapping the precise binding surfaces in membranes between monomers in Bax oligomers that mediate domain swapping, as well as in Bcl-2/Bcl-XL homodimers and $\mathrm{Bcl}-2 / \mathrm{Bcl}-\mathrm{XL}-\mathrm{Bax}$ heterodimers that cannot form large oligomers is critical to understanding this process $[32,53]$. In this context, it is interesting to note that $\mathrm{Bcl}-\mathrm{XL}$ and $\mathrm{Bcl}-2$ can be converted to pro-apoptotic proteins like Bax by caspase cleavage at a site that removes the BH4 region and the unstructured loop [75, 76]. Similarly, binding of the orphan steroid receptor Nur77 converts Bcl-2 to a pro-apoptotic protein [77]. We would therefore predict these changes result in an altered $\mathrm{Bcl}-2 / \mathrm{Bcl}-\mathrm{XL}$ where domain swapping compatible with oligomerization occurs in membranes, and that other mutants of Bcl-2/XL that could swap alpha 5-6 helices similarly would also promote apoptosis. Conversely, Bax/Bak mutants that cannot form large oligomers by domain swapping would not induce apoptosis.

In our model, we also acknowledge that the cytoplasmic form of Bcl-XL and Bcl-2 before helix 5/6 insertion retain other important anti-apoptotic functions such as sequestering BH3 only proteins (Fig. 4). It is possible that sequestering pro-apoptotic $\mathrm{BH} 3$ molecules may be the an- 
cestral function of anti-apoptotic proteins, as it is preserved in C. elegans, where Ced-9 prevents apoptosis by sequestering Ced-4. In this case, the $\mathrm{BH} 3$ protein Egl-1 displaces Ced-4, thereby acting as a "sensitizer" according to the direct activation model. However, Ced-9 does not prevent Bax mediated MOMP [78]. It is possible therefore that Ced-9 does not go through the same conformational change after binding to Egl-1, as Bcl-2 does after binding tBid. Thus the conformational change induced by $\mathrm{BH} 3$ protein binding that results in anti-apoptotic proteins binding to the membrane embedded forms of Bax/Bak, may be a more recent and potent boost to function necessitated by the evolution of multi-domain pore-forming pro-apoptotic proteins in metazoans [79]. The relative proportion of these two binding activities (BH3 protein binding with and without the embedding in membranes and subsequent conformational change) may mediate the variation in overall anti-apoptotic function between the different anti-apoptotic proteins in cells [80].

One significant consequence of the recognition of multiple, regulated conformations of both pro- and anti-apoptotic members of the Bcl-2 family that determine transition from inactive to active forms is that these represent novel targets for drug development. Several agents that target the known sites of interaction between pro- and anti-apoptotic proteins (e.g. BH3 mimetics) are already in clinical development [81], and would be predicted to be active by all three of the models that we have discussed here. However, the embedded together model would also predict that allosteric regulators of the transitions between conformational states represent attractive "drugable" targets that may offer greater specificity. Mapping the surfaces of these conformation-specific domains in the physiologically relevant context of membranes is therefore an important priority [32, 53, 82].

\section{Conclusion}

Some years ago a prescient apoptosis researcher [83] noted that despite the enormous amount of progress (and publications) on apoptosis that have appeared since the original description of the phenomenon in 1972 [84], we were still at the stage of phenomenological description of the mechanisms involved. Since then, the network of combinatorial interactions between different $\mathrm{BH} 3$ proteins, and multi-region antiand pro-apoptotic Bcl-2 family members has been described leading to two current, testable models that each incorporate some of the observations presented here. We have postulated how recent findings from our laboratories and others can be used to reconcile and integrate aspects of these previous models into a new model for the molecular mechanism of MOMP that recognizes the relevance of multiple interactions between proteins and membranes to control conformational switches. The utility and heuristic value of our model will be determined by multiple novel predictions as noted above, and by pointing out relevant physiological interactions that can be measured to allow progress in quantitative modeling of the overall apoptotic process (e.g. [85]) that would pass the critical eye of a determined amateur engineer fixing a transistor radio [83]!

\section{References}

1. Letai A, Bassik MC, Walensky LD et al (2002) Distinct BH3 domains either sensitize or activate mitochondrial apoptosis, serving as prototype cancer therapeutics. Cancer Cell 2:183-192

2. Kuwana T, Bouchier-Hayes L, Chipuk JE et al (2005) BH3 domains of BH3-only proteins differentially regulate Bax-mediated mitochondrial membrane permeabilization both directly and indirectly. Mol Cell 17:525-535

3. Certo M, Del Gaizo Moore V, Nishino N et al (2006) Mitochondria primed by death signals determine cellular addiction to antiapoptotic BCL-2 family members. Cancer Cell 9:351365

4. Wei MC, Zong WX, Cheng EH et al (2001) Proapoptotic BAX and BAK: a requisite gateway to mitochondrial dysfunction and death. Science 292:727-730

5. Cartron PF, Gallenne T, Bougras B et al (2004) The first alpha helix of Bax plays a necessary role in its ligand-induced activation by the BH3-only proteins Bid and PUMA. Mol Cell 16:807-818

6. Walensky LD, Kung AL, Escher I et al (2004) Activation of apoptosis in vivo by a hydrocarbon-stapled BH3 helix. Science 305:1466-1470

7. Kuwana T, Mackey MR, Perkins G et al (2002) Bid, Bax, and lipids cooperate to form supramolecular openings in the outer mitochondrial membrane. Cell 111:331-342

8. Cartron PF, Arokium H, Oliver L et al (2005) Distinct domains control the addressing and the insertion of Bax into mitochondria. J Biol Chem 280:10587-10598

9. Terrones O, Antonsonn B, Yamaguchi $\mathrm{H}$ et al (2004) Lipidic pore formation by the concerted action of proapoptotic BAX and tBID. J Biol Chem 279:30081-30091

10. Annis MG, Soucie EL, Dlugosz PJ et al (2005) Bax forms multispanning monomers that oligomerize to permeabilize membranes during apoptosis. EMBO J 24:2096-2103

11. Dlugosz PJ, Billen LP, Annis MG et al (2006) Bcl-2 changes conformation to inhibit Bax oligomerization. EMBO J 25:2287-2296

12. Yethon JA, Epand R, Leber B et al (2003) Interaction with a membrane surface triggers a reversible conformational change in Bax normally associated with induction of apoptosis. J Biol Chem 278:48935-48941

13. Desagher S, Osen-Sand A, Nichols A et al (1999) Bid-induced conformational change of $\mathrm{Bax}$ is responsible for mitochondrial cytochrome $c$ release during apoptosis. J Cell Biol 144:891901

14. Eskes R, Desagher S, Antonsonn B et al (2000) Bid induces the oligomerization and insertion of Bax into the outer mitochondrial membrane. Mol Cell Biol 20:929-935

15. Wei MC, Lindsten T, Mootha VK et al (2000) tBID, a membranetargeted death ligand, oligomerizes BAK to release cytochrome c. Genes Dev 14:2060-2071

16. Cheng EH, Wei MC, Weiler S et al (2001) BCL-2, BCL-X(L) sequester $\mathrm{BH} 3$ domain-only molecules preventing $\mathrm{BAX}-$ and BAK-mediated mitochondrial apoptosis. Mol Cell 8:705-711 
17. Terradillos O, Montessuit S, Huang DC et al (2002) Direct addition of BimL to mitochondria does not lead to cytochrome $c$ release. FEBS Lett 522:29-34

18. Marani M, Tenev T, Hancock D et al (2002) Identification of novel isoforms of the $\mathrm{BH} 3$ domain protein Bim which directly activate Bax to trigger apoptosis. Mol Cell Biol 22:3577-3589

19. Harada H, Quearry B, Ruiz-Vela A et al (2004) Survival factorinduced extracellular signal-regulated kinase phosphorylates BIM, inhibiting its association with BAX and proapoptotic activity. Proc Natl Acad Sci USA 101:15313-15317

20. Suzuki M, Youle RJ, Tjandra N (2000) Structure of Bax: coregulation of dimer formation and intracellular localization. Cell 103:645-654

21. Sattler M, Liang H, Nettesheim D et al (1997) Structure of Bcl-xL-Bak peptide complex: recognition between regulators of apoptosis. Science 275:983-986

22. Zha J, Wewiler S, Oh KJ et al (2000) Posttranslational Nmyristoylation of BID as a molecular switch for targeting mitochondria and apoptosis. Science 290:1761-1765

23. Hu X, Han Z, Wyche JH et al (2003) Helix 6 of tBid is necessary but not sufficient for mitochondrial binding activity. Apoptosis 8:277-289

24. Kim TH, Zhao Y, Ding WX et al (2004) Bid-cardiolipin interaction at mitochondrial contact site contributes to mitochondrial cristae reorganization and cytochrome $c$ release. Mol Biol Cell 15:3061-3072

25. Gong XM, Choi J, Franzin CM et al (2004) Conformation of membrane-associated proapoptotic tBid. J Biol Chem 279:2895428960

26. Oh KJ, Barbuto S, Meyer N et al (2005) Conformational changes in BID, a pro-apoptotic BCL-2 family member, upon membrane binding. A site-directed spin labeling study. J Biol Chem 280:753767

27. Oh KJ, Barbuto S, Pitter K et al (2006) A membrane-targeted BID $\mathrm{BH} 3$ peptide is sufficient for high potency activation of BAX in vitro. J Biol Chem 281:36999-37008

28. Grinberg M, Sarig R, Zaltsman Y et al (2002) BID Homooligomerizes in the mitochondrial membrane to induce apoptosis. J Biol Chem 277:12237-12245

29. Chen L, Willis SN, Wei A et al (2005) Differential targeting of prosurvival $\mathrm{Bcl}-2$ proteins by their $\mathrm{BH} 3$-only ligands allows complementary apoptotic function. Mol Cell 17:393-403

30. Wang K, Yin XM, Chao DT et al (1996) BID: a novel BH3 domain-only death agonist. Genes Dev 10:2859-2869

31. Ruffolo SC, Shore GC (2003) BCL-2 selectively interacts with the BID-induced open conformer of BAK, inhibiting BAK auto-oligomerization. J Biol Chem 278:25039-25045

32. Tan C, Dlugosz PJ, Peng J et al (2006) Auto-activation of the apoptosis protein Bax increases mitochondrial membrane permeability and is inhibited by Bcl-2. J Biol Chem 281:14764-14775

33. Yamaguchi H, Wang HG (2002) Bcl-XL protects BimEL-induced Bax conformational change and cytochrome $c$ release independent of interacting with Bax or BimEL. J Biol Chem 277:41604-41612

34. Mikhailov V, Mikhailova M, Degenhardt K et al (2003) Association of Bax and Bak homo-oligomers in mitochondria. Bax requirement for Bak reorganization and cytochrome $c$ release. $\mathrm{J}$ Biol Chem 278:5367-5376

35. Pierrat B, Simonen M, Cueto M et al (2001) SH3GLB, a new endophilin-related protein family featuring an SH3 domain. Genomics 71:222-234

36. Takahashi Y, Karbowski M, Yamaguchi H et al (2005) Loss of Bif1 suppresses Bax/Bak conformational change and mitochondrial apoptosis. Mol Cell Biol 25:9369-9382

37. Willis SN, Chen L, Dewson G et al (2005) Proapoptotic Bak is sequestered by Mcl-1 and Bcl-xL, but not Bcl-2, until displaced by BH3-only proteins. Genes Dev 19:1294-1305
38. Wilson-Annan J, O'Reilly LA, Crawford SA et al (2003) Proapoptotic $\mathrm{BH} 3$-only proteins trigger membrane integration of prosurvival Bcl-w and neutralize its activity. J Cell Biol 162:877-887

39. Cuconati A, Mukherjee C, Perez D et al (2003) DNA damage response and MCL-1 destruction initiate apoptosis in adenovirus-infected cells. Genes Dev 17:2922-2932

40. Leu JI, Dumont P, Hafey M et al (2004) Mitochondrial p53 activates Bak and causes disruption of a Bak-Mcl1 complex. Nat Cell Biol 6:443-450

41. Cheng EH, Sheiko TV, Fisher JK et al (2003) VDAC2 inhibits BAK activation and mitochondrial apoptosis. Science 301:513-517

42. Oltvai ZN, Milliman CL, Korsmeyer SJ et al (1993) Bcl-2 heterodimerizes in vivo with a conserved homolog, Bax, that accelerates programmed cell death. Cell 74:609-619

43. Hsu YT, Youle RJ (1997) Nonionic detergents induce dimerization among members of the Bcl-2 family. J Biol Chem 272:13829-13834

44. Hsu YT, Youle RJ (1998) Bax in murine thymus is a soluble monomeric protein that displays differential detergent-induced conformations. J Biol Chem 273:10777-10783

45. Antonsson B, Montessuit S, Sanchez B et al (2001) Bax is present as a high molecular weight oligomer/complex in the mitochondrial membrane of apoptotic cells. J Biol Chem 276:11615-11623

46. Yang E, Zha J, Jockel J et al (1995) Bad, a heterodimeric partner for Bcl-XL and Bcl-2, displaces Bax and promotes cell death. Cell 80:285-291

47. Letai A, Sorcinelli MD, Beard C et al (2004) Antiapoptotic BCL-2 is required for maintenance of a model leukemia. Cancer Cell 6:241-249

48. Nijhawan D, Fang M, Traer E et al (2003) Elimination of Mcl-1 is required for the initiation of apoptosis following ultraviolet irradiation. Genes Dev 17:1475-1486

49. Zhong O, Gao W, Dhu F et al (2005) Mule/ARF-BP1, a BH3-only E3 ubiquitin ligase, catalyzes the polyubiquitination of Mcl-1 and regulates apoptosis. Cell 121:1085-1095

50. Warr MR, Acoca S, Liu Z et al (2005) BH3-ligand regulates access of MCL-1 to its E3 ligase. FEBS Lett 579:5603-5608

51. Jeong SY, Gaume B, Lee YJ et al (2004) Bcl-x(L) sequesters its C-terminal membrane anchor in soluble, cytosolic homodimers. EMBO J 23:2146-2155

52. Wang K, Yin XM, Chao DT et al (1996) BID: a novel BH3 domain-only death agonist. Genes Dev 10:2859-2869

53. Peng J, Tan C, Roberts GJ et al (2006) tBid elicits a conformational alteration in membrane-bound $\mathrm{Bcl}-2$ such that it inhibits bax pore formation. J Biol Chem 281:35802-35811

54. Sharpe JC, Arnoult D, Youle RJ (2004) Control of mitochondrial permeability by Bcl-2 family members. Biochim Biophys Acta 1644:107-113

55. Zhang H, Kim JK, Edwards CA et al (2005) Clusterin inhibits apoptosis by interacting with activated Bax. Nat Cell Biol 7:909-915

56. Cuddeback SM, Yamaguchi H, Komatsu K et al (2001) Molecular cloning and characterization of Bif-1. A novel Src homology 3 domain-containing protein that associates with Bax. J Biol Chem 276:20559-20565

57. Schinzel A, Kaufmann T, Borner C (2004) Bcl-2 family members: integrators of survival and death signals in physiology and pathology. Biochim Biophys Acta 1644:95-105

58. Tan KO, Tan KM, Chan SL et al (2001) MAP-1, a novel proapoptotic protein containing a BH3-like motif that associates with Bax through its Bcl-2 homology domains. J Biol Chem 276:28022807

59. Tan KO, Fu NY, Sukumaran SK et al (2005) MAP-1 is a mitochondrial effector of Bax. Proc Natl Acad Sci USA 102:14623-14628

60. Ohtsuka T, Ryu H, Minamishima YA et al (2004) ASC is a Bax adaptor and regulates the p53-Bax mitochondrial apoptosis pathway. Nat Cell Biol 6:121-128 
61. Dumont P, Leu JI, Della Pietra AC et al (2003) The codon 72 polymorphic variants of p53 have markedly different apoptotic potential. Nat Genet 33:357-365

62. Chipuk JE, Kuwana T, Bouchier-Hayes L et al (2004) Direct activation of $\mathrm{Bax}$ by p53 mediates mitochondrial membrane permeabilization and apoptosis. Science 303:1010 1014

63. Leu JI, Dumont P, Hafey M et al (2004) Mitochondrial p53 activates Bak and causes disruption of a Bak-Mcll complex. Nat Cell Biol 6:443-450

64. Perfettini JL, Kroemer RT, Kroemer G (2004) Fatal liaisons of p53 with Bax and Bak. Nat Cell Biol 6:386-388

65. Park BS, Song YS, Yee SB et al (2005) Phospho-ser 15-p53 translocates into mitochondria and interacts with Bcl-2 and Bcl-xL in eugenol-induced apoptosis. Apoptosis 10:193-200

66. Roucou X, Rostotseva T, Montessuit S et al (2002) Bid induces cytochrome c-impermeable Bax channels in liposomes. Biochem J 363:547-552

67. Goldmacher VS, Bartle LM, Skaletskaya A et al (1999) A cytomegalovirus-encoded mitochondria-localized inhibitor of apoptosis structurally unrelated to Bcl-2. Proc Natl Acad Sci USA 96:12536-12541

68. Poncet D, Pauleau AL, Szabadkai G et al (2006) Cytopathic effects of the cytomegalovirus-encoded apoptosis inhibitory protein vMIA. J Cell Biol 174:985-996

69. Arnoult D, Bartle LM, Skaletskaya A et al (2004) Cytomegalovirus cell death suppressor vMIA blocks Bax- but not Bak-mediated apoptosis by binding and sequestering Bax at mitochondria. Proc Natl Acad Sci USA 101:7988-7993

70. Wasilenko ST, Banadyga L, Bond D et al (2005) The vaccinia virus F1L protein interacts with the proapoptotic protein Bak and inhibits Bak activation. J Virol 79:14031-14043

71. Postigo A, Cross JR, Downward J et al (2006) Interaction of F1L with the BH3 domain of Bak is responsible for inhibiting vaccinia-induced apoptosis. Cell Death Differ 13:16511662

72. Kim PK, Annis MG, Dlugosz PJ et al (2004) During apoptosis Bcl-2 changes membrane topology at both the endoplasmic reticulum and mitochondria. Mol Cell 14:523-529
73. Korsmeyer SJ, Gross A, Harada H et al (1999) Death and survival signals determine active/inactive conformations of pro-apoptotic BAX, BAD, and BID molecules. Cold Spring Harb Symp Quant Biol 64:343-350

74. Schendel SL, Montal M, Redd JC (1998) Bcl-2 family proteins as ion-channels. Cell Death Differ 5:372-380

75. Cheng EH, Kirsch DG, Clem RJ et al (1997) Conversion of Bcl-2 to a Bax-like death effector by caspases. Science 278:1966-1968

76. Clem RJ, Cheng EH, Karp CL et al (1998) Modulation of cell death by Bcl-XL through caspase interaction. Proc Natl Acad Sci USA 95:554-559

77. Lin B, Kolluri SK, Lin F et al (2004) Conversion of Bcl-2 from protector to killer by interaction with nuclear orphan receptor Nur77/TR3. Cell 116:527-540

78. Delavani P, Adrain C, Taylor RC et al (2006) Role for CED-9 and Egl-1 as regulators of mitochondrial fission and fusion dynamics. Mol Cell 21:761-773

79. Aouacheria A, Brunet F, Gouy M (2005) Phylogenomics of life-or-death switches in multicellular animals: Bcl-2, BH3-Only, and BNip families of apoptotic regulators. Mol Biol Evol 22:2395-2416

80. Fiebig A, Zhu W, Hollerbach C et al (2006) Bcl-XL is qualitatively different from and ten times more effective than $\mathrm{Bcl}-2$ when expressed in a breast cancer cell line. BMC Cancer 6: 213

81. Goldsmith KC, Liu X, Dam V et al (2006) BH3 peptidomimetics potently activate apoptosis and demonstrate single agent efficacy in neuroblastoma. Oncogene 25:4525-4533

82. Zhang Z, Lapolla SM, Annis MG et al (2004) Bcl-2 homodimerization involves two distinct binding surfaces, a topographic arrangement that provides an effective mechanism for Bcl-2 to capture activated Bax. J Biol Chem 279:43920-43928

83. Lazebnik Y (2002) Can a biologist fix a radio?-Or, what I learned while studying apoptosis. Cancer Cell 2:179-182

84. Kerr JF, Wylie AH, Currie AR (1972) Apoptosis: a basic biological phenomenon with wide-ranging implications in tissue kinetics. $\mathrm{Br}$ J Cancer 26:239-257

85. Janes KA, Albeck JG, Gaudet S et al (2005) A systems model of signaling identifies a molecular basis set for cytokine-induced apoptosis. Science 310:1646-1653 